\title{
DEVELOPING OPEN SOURCE MATERIALS FOR FOUNDATION PHASE: DIVERSE SPACES FOR COLLABORATION
}

\author{
D. Moodley \\ Molloy College \\ Long Island, New York \\ United States \\ e-mail: desm611@hotmail.com
}

\section{Joubert}

Department of Early Childhood Education University of Pretoria

Pretoria, South Africa

e-mail: ina.joubert@up.ac.za

\section{R. Sookraj}

School of Education

University of KwaZulu-Natal

Durban, South Africa

e-mail: Sookrajhre@ukzn.ac.za

\author{
C. G. A. Smith \\ Department of Applied Languages \\ Tshwane University of Technology \\ Pretoria, South Africa \\ e-mail: smithcga@tut.ac.za
}

\section{P. Singh}

Department of Early Childhood Development

Embury Institute for Teacher Education

Durban, South Africa

e-mail: PrabithaS@eite.ac.za

\author{
Z. Zama \\ Department of Early Childhood Development \\ Embury Institute for Teacher Education \\ Durban, South Africa \\ e-mail: zanelezama42@yahoo.com
}

\section{ABSTRACT}

Determining a space for collaborative activities involves the creation of a unique space which encourages reciprocal learning and the creation of products that can benefit all participants. The aim of this article was to explore the experiences of group members in this collaborative space. The group consisted of lecturers from different Higher Education Institutions (HEIs) tasked to create quality open-source materials for teaching and learning Literacy in Foundation Phase at HEls (coming together and work in one space) in the endeavour to connect and share collaboratively. Selected components of the theories of space suggested by Lefebvre and Soja were employed to explain the data which were gleaned through interviews with all participants in the group. This article makes two important contributions: firstly, it substantively presents a deeper understanding of the experiences of the group in collaborative work and secondly, through the use of a theoretical framework on space, offers insights into the nature of collaboration within diverse spaces.

Keywords: collaboration, diverse spaces, theory of space, development of Foundation Phase materials.

\section{INTRODUCTION}

The European Union, together with the Department of Higher Education funded a large, multidimensional project in South Africa with the general aim to assist the various Higher Education 
Institutions (HEI's) or universities to upgrade their course work done in Literacy in the Foundation Phase. An additional aim was to assist HEIs (HEIs in privileged and underprivileged geographical spaces) in starting Foundation Phase programs. The HEIs involved straddled, different regions in South Africa. The deliverables of the project were to design open-source research-based materials for the teaching and learning in Foundation Phase Programmes. This article commences with the notion of space and how it surfaced in the collaboration of the university lecturers involved in compiling and creating material. It is followed by a discussion on theory of space as engaged with by Lefebvre (1991) and Soja (1996), as valuable aspects proposed by these proponents are incorporated to illuminate the way space surfaces when cooperating. The methodology is presented and a discussion of the findings forwarded through the use of selected theories of space. The idea was to provide material on the intricacies of group work to serve as a basis for other researchers to draw on.

\section{LITERATURE REVIEW}

\section{Background}

The focus in this article is on group work and the way the participants experienced the collaborative space. The space identified in this article covers the physical as well as personal and psychological spaces involved when cooperating on the creation and designing of new teaching and learning material. It also takes cognisance of the relationships and emotions experienced by the participants, as good relations were seen as paramount for a successful collaborative undertaking. The space or area of cooperation thus covers thus more than the mere venue or office where the meetings occurred as the element of distance compelled the participants to connect via internet and to venture to propose ideas to be evaluated by other group members (Lippman 2015, 39).

The value of collaborative work is emphasised as cooperative work can promote academic and social learning facilitating interdependence and interaction on various levels (Kaldi Filippatou and Anthopoulou 2014, 621). In order to arrange the ideas on collaboration within a group, the theories of Lefebvre and Soja were used as guidance to come up with themes to structure our research article. Collaborative work deals to a great extent with the needed space viz. personal space within the group and the collaborative space where communication has to take place in an effort to come up with information on group work among adults at university level. It is paramount to highlight the value of group work, as it is beneficial to the growth of epistemology. Three reasons for justifying the value of collaborative or contextual work are: 
- Knowledge arrived at in a specific context seems to receive legitimisation to add validity to statements;

- $\quad$ Multifaceted ideas are arrived at that gain a predictive nature;

- These group ideas serve as a contextual situation that questions self-demonstrative theories as there are many members involved. We refer to Lefebvre that highlights the concept of planning which in effect refers to a variety of ideas (Vianello 2015, 35).

\section{Social space and collaboration within the group}

Although Lefebvre was a sociologist, and neo-Marxist existential philosopher who believed that revolutionising everyday life in order to help capitalism survive (Molotch 1993, 890), his concepts serve as a useful framework to discuss a collaborative undertaking within a project context. Soja identifies a Firstspace, embracing the real space referring to physical buildings, a Secondspace, which he terms the representational space which is the imagined space and the Thirdspace which he sees as the fully lived space where aspects such as subjectivity, objectivity, consciousness, unconsciousness, everyday life and history are integrated. Lefebvre's $(1991,33)$ concepts of spatial practice, representations of space and representational spaces are combined in Figure 1 to arrive at an enriched perspective of making use of both the ideas of these proponents. Soja's (1996) Thirdspace is consequently added to elaborate on Lefebvre's framework approach. In short the application of his theory will serve as an organiser of the data extracted from the participants in this case study viz.:

- $\quad$ The Firstspace involves the venue where the meetings were schedules for the group;

- The Secondspace involves the dreams that the group members had for an improved product;

- The Thirdspace embraces the group members' subjective responses to their experience of working together, having social contact and coming from different cultural and learning backgrounds. It also points out how the group harnessed the strengths within the group to benefit everyone.

Even though we acknowledge that the history of space cannot be limited to special moments (Lefebvre 1991, 48), it is true that a global look enriches a product. Combining Soja's (1996, 57) concept of Thirdspace (a real and imagined space) and Lefebvre’s concepts of spatiality, sociality and history provide a holistic perspective of the concept of space. According to 
Lefebvre $(1991,46)$ 'It is reasonable to assume that spatial practice, representations of space and representational spaces contribute in different ways to the production of space according to their qualities and attributes, according to the society or mode of production in question, and according to the historical period'.

Rainey (2013) explains the spatial practice by suggesting that social space can be interpreted as a social product. Space reflects the social relations of production and vice versa. These concepts viz. space and social relations are deemed as mutually constitutive in their dialectical relationship with one another. Reciprocation is thus vital in arriving at a product that reflects many perspectives and ways of creating a product such as e.g. open-source material.

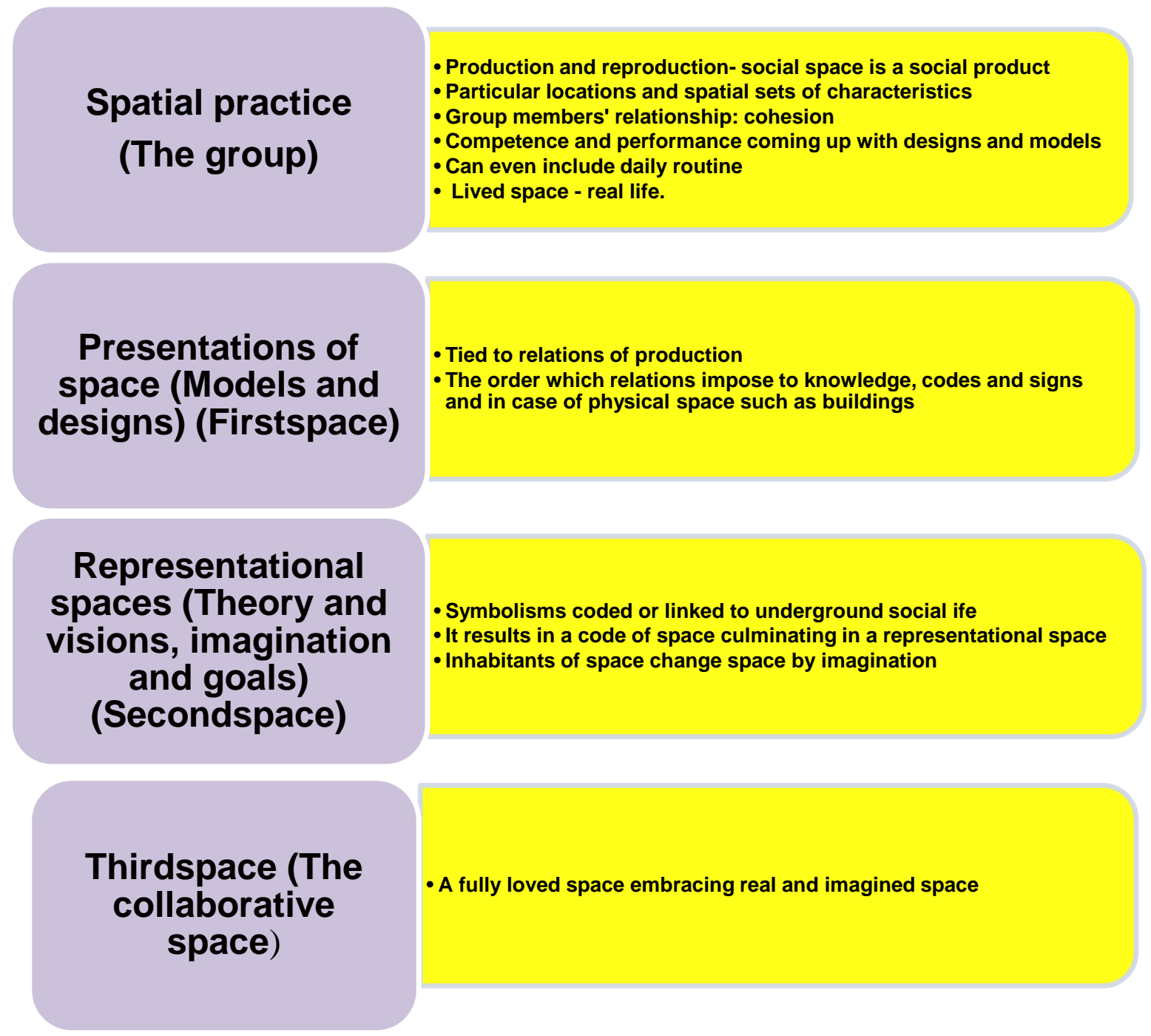

Figure 1: A conceptual framework incorporating Lefebvre's $(1991,33)$ concepts and Soja's $(1996,57)$ Thirdspace

Spatial practice refers to the production of the relationships aiming at objects and members of the group which ensures cohesion of the group members in the group. The representation of 
space refers to the conceptualised space of researchers and of necessity educationalists as planners of curriculum material (Canete 2004).

Representational spaces are affected by changing codes over time. This in fact boils down to a group of people representing the space of educationalists who are impacted over time. Due to the time factor all research is elaborated on or amended due to new findings and technology. Production of space is also linked with history. A former educational regime cannot be interpreted as a mere agglomeration of people and ideas but their thought happened in a space affected by time and history. It is therefore of paramount importance that new products are developed from time to time to ensure that teaching materials at university is keeping abreast with new developments and new knowledge (Canete 2004).

Lecturers can use their knowledge and imagination to affect the Firstspace in practice and come up with the Secondspace or representational spaces to create an enriched product that will be affected over time as it will have to be re-visited at a later stage. This reflective action is a direct result because of the dynamic nature of knowledge and the teaching of such knowledge especially as affected by modern technology in all its forms. These forms can be regarded as assets (taking into consideration the communication aspect such as e-mail communication) and regrettably also detriments (referring to e.g. the negative impact of cell phones on discipline in schools). It can thus be gathered that group members collaborating can work constructively together to build a product together creating a Thirdspace in which the imagined ideas are realised to contribute innovatively to the current knowledge and programmes used at university level. The lecturers who participated all cooperated to apply the above-mentioned principles of optimising the spaces provided to generate new work of a high standard. The interviews conducted cast new light on how the work spaces were experienced. The aim was to create the symbiotic Thirdspace. The meaning of a Thirdspace is discussed next.

The Thirdspace has a symbiotic (mutually beneficial partnership) nature as co-operation is essential in arriving at a quality product that can serve as open-source material. Thirdspace embraces group cohesion. The Firstpace and the Secondspace reach a stage of postmodernist incompletion that is always supplemented by new knowledge. No knowledge can be complete in itself as new developments will affect it.

Implementing Thirdspace in education as explained above will serve as main topics for discussing a collaborative initiative to develop materials for our postmodern space of a forever changing source of data that cannot reach completion. Implementing Thirdspace as a result also implies group cohesion and the social space. The spaces are as follows: 
- $\quad$ The Firstspace involves the models and designs of knowledge;

- $\quad$ The Secondspace embraces the creativity, vision and goals of the group;

- $\quad$ The Thirdspace involves the realisation of the goals and dreams for an improved reality.

In order to merge contributions of Soja and other critics to enrich our focus on collaborative work, ideas to promote harmonious group work that can motivate the participants are also incorporated. These crucial ideas enriching the various learning spaces are discussed next.

Effectiveness of structured co-operative work is vital for sound relationships and an enriched final product. Effective collaboration can directly be linked with Vygotsky's principles of interactive learning. The basic characteristics of group work are:

- $\quad$ Co-operation among the group members to reach common teaching goals;

- $\quad$ Positive interdependence;

- $\quad$ Promotive interaction among the members of the group;

- $\quad$ Collective and individual accountability (Kaldi, Filippatou and Anthopoulou 2014, 621).

Vygotsky maintains that every group member has his/her individual zone of proximal development which should be activated and added to by assistance from others (Wessels 2010, 3; Lippman 2015, 40; Kaldi, Flippatou and Anthopoulou 2014, 621).

When investigating ways to attain collaborative members should be taught how to:

- $\quad$ co-operate;

- $\quad$ communicate socially and the process is more personal as they share, advise and persuade each other;

- $\quad$ help each other to practice and entrench certain skills;

- $\quad$ help members to clarify and to develop higher order skills;

- $\quad$ enable members to pool resources and respected each other;

- $\quad$ identify errors and sorted these out;

- $\quad$ help members to be knowers in lieu of assimilators (Wessels 2010, 9).

The idea of a collaborative learning space can also be connected with the notion of a life space where group members can connect. The learning space becomes a life space where members psychologically connect and where they share subjective experiences. The life and learning 
space as collaborative space requires taking cognisance of needs, goals, unconscious influences, beliefs, memories, social and even political events, external needs and external demands are said to impact the members of the group (Kolb and Kolb 2005, 199).

Issues such as rejection and unhappiness within a group should be addressed. If group members feel rejected, they may be negatively impacted in their effort to learn. Support and cohesion within the group is therefore of the utmost importance especially when it comes to the execution of tasks at hand (Mary 2015, 125).

The manner in which those who co-operate to learn is an essential area of research. Cooperatives have the potential to generate new knowledge that can alter the systems, culture or structure of the co-operatives. Situated learning can take place if group members reach out in an effort to learn from other members. This process of situated learning can be regarded as legitimate, peripheral participation. The shared ideas can then form a foundation for learning (Hartley 2014, 715-716).

Collaborative spaces should be designed to promote flexibility and fluidity that encourage creative thinking. The learning spaces of collaborative work should be both differentiated and integrated at the same time. The group members can each be busy with a separate task. The collaborative space should thus cater for different modes of learning such as: independent learning, small group learning and one-on-one learning. The value of break-out niches to allow privacy can serve as extensions to instructional spaces (Lippman 2015, 39).

Mata-Rivera, Torres-Ruiz, Guzman, Moreno-Ibarra and Quinterro (2015, 829) assert that collaborative learning can also appear in social networks and that the use of technology can be conducive to share opinions regarding the group's aims and goals. Technology is inseparable from modern group work. It can therefore be gathered that technology will form part of the Thirdspace in this case study.

A collaborative study conducted by Biasutti $(2015,117)$ yields interesting information that can assist with a study on group collaboration even though it was conducted within the realm of music. She asserts that much creativity is sparked off in a collaborative domain giving rise to furthering individualistic analysis of cognition (Biasutti 2015, 117). Constraints and reflection on what is done within the group is vital to growth. Biasutti $(2015,119)$ maintains that when communicating within a group there are many factors involved such as states of consciousness i.e. flow. Flow refers to a state of mind that combines factors such as cognitive, affective and physiological factors. Flow can inspire peak performances embracing: challenge and skill balance, merging action and awareness, identifying clear goals, providing unambiguous feedback focus on the task, losing self-consciousness. Group flow will occur if 
the members are all working in the same direction towards goal achievement (Biasutti 2015, 119).

\section{RESEARCH METHODOLOGY}

\section{Participants}

The participants were all lecturers at tertiary level with the exception of one participant who was working on her masters and was still working at a school. They all participated willingly to reflect on group work done at university level.

\section{Instrument}

In-depth inquiry can be regarded as the hallmark of qualitative research and involves an attempt to understand the case under investigation in its natural setting (Rule and John 2011, 61). Rule and John $(2011,64)$ posit that interviewing is one of the most popular methods of qualitative research. The approach used was a qualitative approach focusing on subjective experiences arranged according to themes. Saldana (2010) asserts that rich discoveries lead to themes that can form part of the discussion. The instrument used in this study included structured questions, compiled as part of the interview questions. The essence of this article covers the reflections of participants engaged in group work. Compare the next section on the methodology.

\section{Methodology}

Silverman $(2005,25)$ is of the opinion that if the researcher is concerned with people's life histories or everyday behaviour the qualitative method should be used. Qualitative research methods embrace the structured interview allowing for subjective responses (Silverman 2005, 25). The focus group interview is initiated by responding to questions and interaction among participants is facilitated (Rule and John 2011, 66). In order to incorporate every one of the six researcher's unique spaces with the unique circumstances, presentational space and representational space as well as her Thirdspace, structured interview questions were compiled and employed as instrument to elicit the unique experiences. This allowed every researcher to contribute to the areas of difficulty in her unique contribution to Literacy and more specifically to the area of English. The method is thus a qualitative research method spanning interviews and responses from researchers to identify problem areas and indicated benefits in designing and producing a collaborative paper (Bless, Higson-Smith and Sithole 2013, 21).

This article followed a descriptive research approach to determine more about the opinions 
of the participatory researchers towards the end of the EU project. According to Bless et al. $(2013,17)$ qualitative research is flexible, can be small in size, reflects subjective opinions and seeks to understand the phenomenon studied from the unit of analysis. The researchers involved could not be seen as representative of all participants involved in the EU project, yet there might be transferability. The interviews were conducted orally and data were grouped according to themes and written down.

\section{FINDINGS AND DISCUSSION ACCORDING TO THEMES}

\section{Introduction}

The themes identified can be linked with the areas as proposed by Lefebvre and Soja in the literature review. They embrace spatial practice and group work, Firstspace (buildings environment and products), Second space (creativity and collaboration) and Thirdspace as the ideal space.

\section{Spatial practice and group work: academic cohesion and collectivity}

Barron and Darling-Hammond (2014) have proven that inquiry-based teaching involves inquiry-based minds which confirm that involvement leads to an improved understanding. Working together as a group has advantages; it deepens the interpretation and understanding of knowledge. The group becomes a supportive environment to stimulate improved performance. The following aspects as mentioned by Barron and Darling-Hammond (2014) also served as project-based pathways to determine the group's focus viz.: centrality to the curriculum, driving questions to lead to central concepts, investigations that were inquiry-based, tasks that were group-driven rather than just being predicted by one university, and focusing on authentic problems experienced by students when learning.

The aspect of cohesion among a group can be elucidated from a social perspective. In order to produce a space of reconciliation and effective learning, group members should collaborate and share their knowledge building a product together. Good communication is the key to cohesion in the group. Identifying strengths can lead to optimal application of resources. Various cultures within the group should be seen as complimentary and not as an element to disrupt being in sync. According to (Wessels 2010) culture of people also embraces arts, beliefs and social instruction that are characteristic of a group of people.

The following key strengths were identified within the group viz.: The sharing of common knowledge, the level of engagement in the subject, the cordial participants and the willingness 
of participants to assist especially when physically present. There was a lot of appreciation for the impressive knowledge base especially in the Foundation Phase and Literacy component. Members had published and worked in the field already. Apart from learning from the members within the group there was a lot of sharing of knowledge with other groups that enriched the work done by a specific focus area. The project leader was also given a lot of praise especially in the way that he drove the project and engaged with participants as he had a very user-friendly and encouraging approach making everyone feel welcome to contribute, even if making a small contribution. The presence of diverse representations (teachers and academics alike) also added to the scaffolded knowledge.

The overall perception reflected a very positive reaction to the co-operation within the group. Participants realised the value of learning from one another as they were working on the tasks assigned to them. They connected well and felt the common goal of developing materials for literacy joined them to work collaboratively in order to create a new product.

Participant A noted: 'I immediately realised that we were potential candidates to work collaboratively towards a common purpose which was Foundation Phase literacy. This was impressive that we could just embrace each other academically.' She continued to add: 'The only weakness is that when physically together, the group is strong and consolidated but when working from a distance this space dissipates somewhat.'

Participant B remarked: 'I was immediately struck by the cordial spirit of the group. Essentially when considering that participants were unknown entities from at least three different institutions but we shared a common purpose, viz. literacy issues.’

Participant $\mathrm{C}$ emphasised the value of genuine team-work that could be regarded as the strength of the group work done: 'We shared the same interests which was research. We could enhance each other's learning through collaboration. The genuine teamwork was evident. We were from diverse backgrounds and this was stimulating.'

Participant E emphasised the value of inter-institutional collaboration as contact with other tertiary institutions was very scarce due to money constraints and physical distance.

Participant F explained that the opportunity to get to know other colleagues in a group, working at different universities provided an opportunity for judgment of character in the sense as to determine reliability and academic expertise in order to support and get support for future activities.

According to Du Plessis, Conley and Du Plessis (2007, 30) co-operative learning means working together achieving the same goal. They propose that goals must be set clearly ahead of time, the learning area for the purpose of developing material must be explored and everyone 
must know exactly what is expected of him/her. Group members should focus on joint group decisions as everyone feels involved and responsible and should provide and share resources. Mixed groups consisting of various cultures is ideal as many other cultural groups will be impacted instead of just reaching one cultural group. A system of reward should be developed as it will motivate group members; time should be made for reflection.

Killen (2013, 215-217) focuses on the pre-requisites of successful co-operative learning. According to him there must be positive interdependence, ongoing direct interaction, individual accountability, appropriate interpersonal skills, and a certain amount of reflectivity. Cooperative learning also relies on incentives as part of rewarding the members for their responsible participation.

Every members' unique talents can enrich the groups' joint effort to reach the goals identified. The human intentions to follow the same goal can also be interpreted as following the same intentions. It is through same intentions that space is produced (Molotch 1993). It is also through collective experience and individuality that the thinking is taken further to achieve learning in a social group (Soja 2013).

\section{Firstspace: Exclusive academic space (more epistemological space) and geographical space}

By co-operating the group creates a conceptualised space of their own. A space to share knowledge irrespective of different cultures, perceptions and background (Canete 2004). The knowledge that is focused on in this article is the learning and teaching of English at university level. The participants created a space of their own. Topics dealt with were topics such as the four basic learning skills viz.; listening, speaking, reading and writing. Materials developed were intended to serve as open-source support material to all universities and to benefit academics and students. The physical space implies the created space such as at meetings where the EU enabled all participants to communicate. Meetings were held at venues such as hotels with conference facilities where a larger group could be accommodated and where crosscommunication even among groups working on the various topics such as Literacy, Mathematics and Life skills could take place. Joubert, Bester, Meyer and Evans (2013) identify these aforementioned learning areas as aspects to cover when teaching Literacy at university level for Foundation Phase teaching and learning.

One of the aspects that was difficult to deal with was the physical distance that hampered communication among members because participants were from different areas in the country (virtual communication). The majority of the group members were very positive about their 
collaboration within the group despite the fact that contact sessions were kept to a minimum, but technology allowed communication when necessary though a real-life situation provided the detail of communication such as the non-verbal communication as well, which made it more effective. There were two members that felt doubtful about their own capabilities as they both had only recently completed their post graduate studies and felt that they lacked knowledge and confidence to communicate effectively. Compare the following remark by Participant D:

\begin{abstract}
'Initially I gathered that I could not compete because I was working with members who were highly qualified and I had just obtained my Ph.D. Members were already authors of articles and also books. I felt a little alienated. My limited knowledge in terms of materials development for the Foundation Phase and communication was a problem.' She continued to say: 'Most of our meetings were at UKZN and all the venues were within the reach. However, it was very difficult after the planned meetings. As I am a teacher and not working fulltime at a University and also doing Masters it was very difficult. I sometimes experience the internet problem when not in the University and that affected my research together with the Project.'
\end{abstract}

Participant E also felt a bit alienated:

I was affected by being a beginner writer with less university experience. I felt that I have less to contribute to the group and had feelings of intimidation since I was only doing Masters in Education during that time.

Participant E also identified the inability to mobilise when not together physically as a problem that exacerbated her isolation and feelings of being alienated.

According to Participant $\mathrm{F}$ the step-by-step effort to find common ground and the establishment of mutual understanding were of crucial importance to work together despite differences in personalities as some participants were more task-orientated, introverted and had to adjust their perspectives to create a strong foothold for good communication and cooperation. The aim of working together could be realised only by connecting well with fellow group members and to apply each member's strengths and accept the small differences even in the capacity to produce more or less material due to different constraints.

Participant $\mathrm{F}$ further maintained that engaging more on an informal level could have helped with a better understanding of where and what each member's initial strengths were. Some group members also joined later than others which also affected the cohesion of the group as everyone was then already so focused on producing material on the topic he was supposed to have covered. Yet the add-ons did make a contribution overall and in the final contact sessions there was a more sincere effort to understand each other's needs. New members became friends that would later support each other emotionally and academically. 


\section{Secondspace: Representational space (changing space by imaginative and creative thinking)}

The representational space involves the area where creative thinking skills are used to stimulate the imagination (Lefebvre 1991, 33). The representational space will change over time and is produced by spatial codes and fragments of discarded codes and even echoes of revolutionary codes. It can be gathered that creative thinking involves the production phase of the undertaking to create a space to develop materials to develop. In order to change the existing codes and products the imagination is necessary to aid change.

According to (Prentice 2010, 154) participants need to be presented with rich opportunities to engage with the world in a different fashion. Imaginative connections can be drawn between past and present experiences. Inquiry, reflection and criticism all form an integral part of the creative skills. Creativity is seen as the gate that can be opened to a better world. In order to escape the 'straightjacket' of existing spaces and to arrive at a more learner-centered space, collaboration and employing the imagination to access even the abstract can contribute to the creation of original products that can benefit man. The contributions by all researchers are thus creatively achieved and collated in a guide with the relevant newly created ideas on the topics in question.

As for the products created a variety of contributions saw the light. The members were all allowed to focus on a topic that interested them within the indicated field of Literacy. The specific group focused on EFAL and the four language skills. All the members contributed to create unique PowerPoints each all based on listening, speaking, reading and writing. Additional PowerPoints on creativity were added as creativity was identified as a crucial aspect in preparing students to develop new product themselves. Apart from the PowerPoints, each member contributed to a thematic guide by adding her ideas on aims, purpose and more specifically assessment tasks. It was a challenge to convince everyone to do the extra work of designing the guide with the indicated requirements and criteria suggested but eventually it was done. Compare the following statements:

Participant D: 'A thematic guide is vital in guiding the lecturers using our products to use it effectively and to put the PowerPoints created to good use. We needed to find criteria to write the thematic guide and these criteria were given to all.'

Participant F: 'I thought the PowerPoint slides to be self-explanatory and the additional thematic guide to be unnecessary as the lecturer will use the slides and make handouts to the students or even store them on e-classroom to consult.'

Even though everyone did not do the thematic guide in such detail, the guide was created and 
guidance provided. Some added more to the slides and others more to the guide, but the group managed to pull it off, accepting diverse perspectives but without causing a divide due to differences.

Participant E was of the opinion that it was best to allow for a few differences and to meet half way. Due to the strengths within the group and the support they gave each other the group managed to complete the final product. Apart from lecturing material, there were also members in the group that were supported by the EU and their universities to attend conferences and the attendance of conferences gave rise to journal articles and even to a group article. The result of EU encouragement and support are already traceable in the ripple effect of producing more material and to keep the academic argument flowing. The different members also benefited with their variety of strengths and knowledge as the group work taught everyone something. The benefits were numerous.

The participants agreed that the value of creative thinking, and expanding perspectives to communicate across parameters thinking outside the box were regarded as crucial factors to aid in material writing. To be creative also means to try to be innovative which can also lead to conflict among the group members, but it was handled excellently by the group leaders. The leaders with their warm personalities could diffuse all the possible conflict and due to the venturesome attitudes original products could be created. There was amongst others the decision to produce a new guide and all group members had to support. Participants learnt to adapt and scaffold, embracing each other's' creative forte. The participants who felt less confident also buckled up and added to the corpus of material created as they did peer assessment and sought advice. Compare the following remark by Participant A:

I was involved in the creativity of materials development which stretched my imagination a bit. I created a PowerPoint on teaching creatively in the Foundation Phase. This was a bit challenging as it was the first time I was involved in materials development. Creativity in Foundation Phase teaching has become crucial for pre-service teachers. Students will have an idea of what creativity is all about and will foster it in their teaching. Some teachers are just not inherently creative so this will enable them to participate in creative development.

Participant $\mathrm{C}$ added that doing research can most definitely enhance creativity and enrich the final product. She exclaimed that: 'I am an experienced Foundation Phase teacher and I already used my creative side to enhance lessons. But in terms of materials development I had to research intensively.’

Participant B asserted that in their case they worked with creativity and the topic needed to be interrogated in a different and novel way. They were impelled by the very material that they were producing to be creative every step of the way. They needed to design materials in a 
way that made pre-service teachers think creatively. She continued to say that:

This is one of the demands currently expected of teachers globally and also in South Africa to create unique and appropriate learning opportunities and environments and to nurture the development of creative thinking abilities among learners. This presentation will enable student teachers and practitioners to foster creativity in a more favourable way and provide ideas to help create their own curricular designs. Students will be able to work creatively since they have an institutional responsibility for leading developments in teaching and learning.

Participant D commented on the problem of upgrading oneself within the field of Foundation Phase teaching and learning, as not everyone was exactly trained as a Foundation Phase teacher or lecturer. Participant D continued to say that:

We had to become familiar with the literature in order to develop the materials. This meant researching the subject carefully and selecting readings appropriate to the subject of creativity in literacy teaching.

Participant $C$ reiterated that creativity also necessitates the generation of new knowledge. She said that:

I thought of developing the material that will assist learners to learn new knowledge and to develop. My focus was on rural schools. I noticed that most rural schools were using codeswitching and it was important to assist and show how it can be used in a way that new language is developed. This was one important theme that emerged from my study. Putting my ideas creatively in writing affected me in developing material of high standard.

Participants E and F agreed with Participant C on the challenging nature of venturing to create new material and agreed that to make a start and by putting ideas in writing helped a lot to look in retrospect and adjust, and add in order to cotton onto the product, refining and creatively improving it. The product was creatively improved on several occasions until they were handed over to the appointed editor.

\section{Thirdspace: the ideal and imagined space}

Thirdspace encompasses epistemology, historicity and ontology. Thirdspace is a space that is more open to otherness and a continuing expansion of knowledge (Soja 1996, 61). According to Kramsch (2012) Soja is aware of the tripartite overlapping levels of spatial injustices. His perspective includes an identification of the external creation of unjust geographies due to political decisions. Relevant instances extend from apartheid as formerly exercised by South Africa and parallel endeavours at the colonial management of space. Segregation was the order of the day in the past when apartheid was still followed. 
According to (Nordquist 2013) Soja intends to establish a concept of social justice by applying a theory of space. Soja seeks, and finds, spatial justice in social justice actions and he focuses on conventional accounts of coalition-building politics embedded in social justice battles. Social justice seems to have an explicit spatial aspect. Linking education and the development of literacy awareness in schools and more specifically in Foundation Phase, necessitate an uplifting of especially the rural areas where schools are still battling to reach the level of privileged city schools. The ideal situation is to upgrade the protective circumstances of rural schools and to assist with problems of city schools such as the problem of youngsters growing up in an environment which is not safe. The geographical area involves certain characteristics that label the schools geographically as privileged, flourishing and organised versus schools that are deprived due to poverty and a shortage of money. It is the real Thirdspace where the goals of the ideal school are married with the true challenges schools are facing which impact on the training of education students. It is also part of the collaborative initiative to develop an awareness of the geographical spaces the learners under investigation were involved in. Lecturers as researchers could then suggest solutions constructively due to enriched interaction.

As for the physical space the overall decision was a resounding message of praise as each and every one appreciated the privilege to be able to travel and make use of a high standard of accommodation. Members admitted not having the privilege of proper accommodation in the past and for three of the members it was a first experience of visiting a beautiful hotel. They all felt very special and the remarks of praise included utterances such as this one by Participant A:

Venues were quite inspiring. This was a luxury for me as I have not travelled very much in terms of working collaboratively. Salt rock was most convenient for me as I live in Ballito.

Participant E was also extremely impressed by Salt rock as a venue as the beautiful views from the rooms and the working area next to the sea were unforgettable and priceless. Compare the following remark:

I can never be more grateful for such a privilege and would like to thank the EU for providing us with such opportunities. I could never do this. It was a first for me and I am not that young anymore.

Participant D commented on the suitability of the venues:

Venues were inspirational - ideal for work productivity. One had time blocked out to develop and discuss materials over two days. This is a luxury for many staff members that are committed to 
teaching and other university/school commitments.

Participant E remarked:

Given time out to dedicate to this alone impacted on how we were all able to produce effective materials. The ambience was great and you had access to other members of the group who were on site - this is not possible when staff is from different institutions.

The general feel of gratitude for such a privilege to visit other beautiful places in our country resonates across other groups as well. The group all agreed that the carefully selected venues, benefitted all and sundry. When creating a new product the inspiration drawn from the surroundings seemed to be crucial as an incentive and support to these participants as the physical buildings and environment impacted them to produce better products.

Group members had to familiarise themselves with materials produced and all the comments and suggestions in modifying and improving the end product. Participant A postulated that ideally collaborative work is best done when the group is together, interacting and brainstorming together, where there is a continuous flow of ideas by members in an uninhibited way. An ideal working space would also entail making use of more face-to-face interactions with group members, sharing ideas, articles, ways in which to present materials and artwork.

Participant B said that: 'More face to face interactions - inter-institutional collaborations can happen on virtual space (Skype) especially when these sessions can be systematically organised.’

Participant C commented on the ideal situation of expanding knowledge of Foundation Phase literacy specifically. There should be a sense of ownership of the materials developed as a group. A new wave of networks should be the goal such as to become examiners, investigate publishing possibilities and conferencing papers and to enrich each other so that each member can benefit from the contact she had with the group.

There was a plea for nurturing the opportunities given to establish academic and social ties and continue to benefit everyone who participated irrespective of how big or small the contribution was as it was in the end about support and giving more than receiving that allowed everyone to shine and feel motivated. A realistic participant warned about romanticising the project as she contended that: 'systems must be in place and the finances available to support the dynamics of collaborative work'. While work and knowledge output were done in personal space, the structure and content, the arrangement of the materials, the editing and proofreading were best completed in face-to-face interactions. 
Compare the last few comments. Participant E: 'I think technology is so advanced, there could be more organised Skype sessions to improve timeous collaboration'. Participant D: ‘My gain was immense being a new Ph.D. graduate and my association with such experienced academics which I am so grateful for'.

\section{CONCLUDING REMARKS}

The advantage that the group had was that it was small enough to ensure good communication and group cohesion. Collaborative work always remains a challenge especially with people who have a lot of expertise. Due to the positive spirit and good leadership group cohesion could be achieved and an effect of flow could follow.

The Firstspace posed the challenge of the geographical space, taking into account the difficulty to connect physically, as the group members all came from different areas and provinces.

The creative Secondspace proved to be a space drawing on all the creative strengths within the group. All contributions counted and each creative thought could be employed to benefit the group. As for the collaborative Thirdspace it was evident that the ideal collaboration would always remain a challenge yet using all contributions positively helped to create an ideal product and to reach an ideal space although any space can still be improved.

Lefebvre's tenets on space and how space is filled combined with Soja's Thirdspace serve as an approach to present all the data collected from the respondents of the group working on Literacy. Focusing on English Home (EHL) and First Additional Language (EFAL) to communicate experiences on working together could be viewed from the perspective of Soja and Lefebvre. Co-operative learning by adults is regarded as an area of neglect in the social sciences realm of research papers (Erichsen and Goldenstein 2011). Providing information on co-operative learning across different spaces is also an endeavour to enrich the growing corpus of information on group work.

\section{REFERENCES}

Barron, B. and L. Darling-Hammond. 2014. Powerful learning: Studies show deep understanding derives from collaborative methods. Edutopia (The George Lucas educational foundation). http://www.edutopia.org/inquiry-project-learning-research (accessed 26 March 2014).

Biasutti, M. 2015. Creativity in virtual spaces: Communication modes employed during collaborative online music composition. Thinking skills and creativity, 17: 117-129. http://dx.doi.org/ 10.1016/j.tsc.2015.06.002 (accessed 8 August 2015).

Bless, C., C. Higson-Smith and S. L. Sithole. 2013. Fundamentals of social research methods. An African perspective. Cape Town: Juta.

Canete, A. 2004. The production of space by H. Lefebvre. Book report. http://thinkingculture. 
blogspot.com/2004/12/production-of-space-by-h-lefebvre-aloy.h... (accessed 26 March 2014).

Du Plessis, P., L. Conley and E. du Plessis. 2007. Teaching and learning in South African schools. Hatfield: Van Schaik.

Erichsen, E. A. and C. Goldenstein. 2011. Fostering collaborative and interdisciplinary research in adult education. Interactive resource guides and tools. Sageopen. http://sgo.sagepub.com/ content/early/2011/04/28/2158244011403804.full.print? (accessed 20 March 2014).

Hartley, S. 2014. Policy arena: Collective learning in youth-focused co-operatives in Lesotho and Uganda. Journal of International Development 26: 713-730.

Joubert, I., M. Bester, E. Meyer and R. Evans. 2013. Literacy in the Foundation Phase. Hatfield; Van Schaik publishers.

Kaldi, S., D. Filippatou and B. Anthopoulou. 2014. The effectiveness of structures co-operative teaching and learning in Greek primary school classrooms. Education 3013 42(6): 621-636.

Killen, R. 2010. Teaching strategies for quality teaching and learning. Cape Town: Juta.

Kolb, A. Y. and A. Kolb. 2005. Learning styles and learning spaces: Enhancing experiential learning in higher education. Academy of Management Learning \& Education 4(2): 193-212.

Kramsch, O. T. 2012. Edward W. Soja, Seeking spatial justice. Publicado en Espacialidades 2(2) JulyDec: 214 -219. http://espacialidades.cua.uam.mx (accessed 26 March 2014).

Lefebvre, H. 1991. The production of space. Translated by Donald Nicholson-Smith. USA: Blackwell publishing.

Lippman, P. 2015. Designing collaborative spaces for schools. Thoughtfully designed learning environments can help students work together more effectively. The Education Digest January: $39-44$.

Mary, L. 2015. Fostering positive peer relations in the primary classroom through circle time and cooperative games. Education 3-13, International journal of primary, elementary and early years education 42(2): 125-137. http://dx.doi.org/10.1080/03004279.2012.662239 (accessed 8 August 2015).

Mata-Rivera, F., M. Torres-Ruiz, G. Guzman, M. Moreno-Ibarra and R. Quinterro. 2015. A collaborative learning approach for geographic information retrieval based on social networks. Computers in human behavior 51: 829-842. http://dx.doi.org/10.1016/j.chb.2014.11.069 (accessed 8 August 2015).

Molotch, H. 1993. The space of Lefebvre. Theory and Society 22: 887-895. http://www.jstor.org/ stable/658004 (accessed 26 March 2014).

Nordquist, E. 2013. Seeking spatial justice by Edward W. Soja. Contemporary Political Theory 12: e16e18. doi:10.1057/cpt.2011.40.

Prentice, R. 2010. Creativity: A reaffirmation of its place in early childhood education. Curriculum Journal 11(2): 145-158. http://www.tandfonline.com/page/terms-and-conditions (accessed 16 June 2013).

Rainey, M. 2013. An introduction to the introduction to Henri Lefebvre's The production of space. NXRB (The Newcross review books). http://newcrossreviewofbooks.wordpress.com/ 2013/01/15/anintroduction-tothe-introduction-to... (accessed 26 March 2014).

Rule, P. and V. John. 2011. Your guide to case study research. Hatfield: Van Schaik publishers.

Saldana, J. 2010. The coding manual for qualitative researchers. London: SAGE.

Silverman, D. 2005. Interpreting qualitative data. Methods for analyzing talk, text and interaction. London: SAGE.

Soja, E. 1996. Thirdspace. Mladen (Mass): Blackwell.

Soja, E. 2013. There's no space like home. From Bachelard to Soja and all the spaces in between. http://2113humtheresnospacelikehome.wordpress.com/soja/ (accessed 18 March 2014).

Vianello, M. 2015. New rights and the space practices: Italian contributions to a theory of the urban 
commons. Footprint Spring: 35-50.

Wessels, M. 2010. Practical guide to facilitating language learning. Cape Town: South Africa: Oxford. 